Philologica Canariensia

Revista de Filología de la Universidad de las Palmas de Gran Canaria

20 (2014), eISSN: 2386-8635

DOI: en trámite

\title{
EL PENSAMIENTO CLÁSICO EN LA POESÍA ESPAÑOLA DE HOY: EL PLATÓN DE LOS POETAS
}

\author{
Josefa Álvarez \\ Le Moyne College, Syracuse (E.E.U.U.)
}

\begin{abstract}
RESUMEN
La poesía contemporánea, capaz de establecer un diálogo constante con distintas tradiciones y épocas diversas, contiene interesantes lecturas de la filosofía platónica que son rastreables en la obra de autores como Aurora Luque, Chantal Maillard, María Sanz, Josefa Parra o Alberto Tesán y que revitalizan por tanto el pensamiento clásico en la contemporaneidad.

Palabras Clave: poesía española contemporánea, platonismo, Chantal Maillard, Aurora Luque, María Sanz, Josefa Parra, Alberto Tesán.
\end{abstract}

\section{ABSTRACT}

Contemporary poetry, and its capacity to enter into a constant dialogue with different traditions and periods, contains interesting readings of Platonic philosophy. These readings, which can be traced in the work of such writers as Aurora Luque, Chantal Maillard, María Sanz, Josefa Parra or Alberto Tesán, revitalize Classical thought in the contemporary scene. KEYWORDS: contemporary Spanish poetry, Platonism, Chantal Maillard, Aurora Luque, María Sanz, Josefa Parra, Alberto Tesán. 
Si algo define a la lírica española actual, como Francisco Díaz de Castro y Almudena del Olmo bien acotan en la introducción a su recién publicado estudio Versos robados, haciéndose eco de la terminología de Genette ${ }^{1}$, es su carácter de "escritura palimpsestuosa... en contacto tanto con la tradición clásica propiamente dicha como con otros textos procedentes de tradiciones particulares muy heterogéneas y no siempre estrictamente literarias." (8). Teniendo clara conciencia de ello, es la intención de este trabajo mostrar cómo la presencia de la Grecia antigua se revitaliza en la poesía española actual a través del estrecho diálogo que esta mantiene con algunas de las figuras más destacadas de la filosofía clásica y sus doctrinas. Nos interesa analizar en concreto el caso de Platón y su escuela, en especial en los poemarios Camaradas de Ícaro (2003) de Aurora Luque y Matar a Platón (2004), de Chantal Maillard, si bien no hemos querido pasar por alto algunos poemas de otros autores significativos al respecto. Sabedores de que es un aspecto que podríamos estudiar en muchos otros poetas de hoy ${ }^{2}$, hemos optado por seleccionar textos de algunos que se aproximan o bien a la línea de acercamiento al filósofo elegida por Luque en el mencionado poemario, como es el caso de "Busca a esos amigos fieles que nunca te cerrarán las puertas de sus libros" (Tu lumbre ajena, 2001) de María Sanz, o bien a la postura crítica de Maillard que igualmente encontramos en los poemas "Xenócrates recuerda a una mujer" (Elogio a la mala yerba, 1996) de Josefa Parra y "Platón aconseja a un guardián de la República" (El mismo hombre, 1996) de Alberto Tesán.

Se aprecia, pues, en todos estos autores una doble tendencia con respecto al padre del idealismo filosófico. Por un lado, encontramos la reivindicación, como apoyo de ciertas reflexiones metapoéticas, de algunas de las ideas expuestas en el Fedro sobre la imposibilidad del lenguaje de traducir la realidad y sobre la figura del poeta como iniciado por cuya boca se expresa la divinidad. Por otro, la crítica de otra imagen muy distinta del poeta como imitador de la realidad que se ofrece en La República e incluso el ataque frontal a los fundamentos del idealismo filosófico que con Platón sentara sus bases en la historia del pensamiento occidental.

Analicemos en primer lugar el caso del Fedro. Leemos en un pasaje de este diálogo: "El que piensa que el dejar un arte por escrito, y de la misma manera, el que lo recibe, deja algo claro y firme por el hecho de estar en letras, rebosa ingenuidad" (275 c). A dicho planteamiento se acerca Aurora 
Luque en su poemario Camaradas de Ícaro. La voz poética habla, en el poema inicial que proporciona el título al conjunto, de la erosión de las palabras, esto es, de su desgaste, y del hecho de que ellas formen parte del material con el que los "camaradas de Ícaro" construyen sus efímeras alas: "palabras sacudidas por latidos / o palabras huyendo de sí mismas / con su erosión a solas" (9). Y no es esta la primera vez que Luque se hace eco de la imposibilidad de la palabra para traducir la vida. Ya en su anterior poemario, Carpe noctem, la voz poética de "Cartografía" se expresa con rotundidad en este sentido: "Hay regiones en la vida que prohíben / su paso a los poetas. 'Prohibido invadir con palabras.'”'(30)

Otro aspecto del mismo diálogo que es igualmente evocado con complicidad en Camaradas es la famosa teoría del ala. Constancia de ello deja Luque en el título del poemario, al elegir como motivo al audaz Ícaro que, con frágiles alas de cera, trata de acercarse más y más al sol. A través de la manía, una de cuyas facetas es inspirada por las Musas, se alcanza la belleza, nos dice Platón. Y eso, alcanzar la belleza, es uno de los logros de los poetas inspirados o, como los denomina Luque, de los "camaradas de Ícaro". Ellos son los elegidos, los únicos que, con su palabra alada llegan a ese elevado territorio y, como recompensa, descansan plácidamente en el Elíseo, donde la poeta los sitúa en la parte final de su poemario: Hölderlin, Keats, Dickinson... Sólo ellos tienen el privilegio de recibir las palabras "densas, plenas de sî" " Nota a Emily Dickinson", 60) o poseer el "don de los himnos plenos" ("Al enviar sus libros a la torre de Hölderlin", 64). Su simpatía hacia esta doctrina platónica queda patente ya en Hiperiónida (1982), su primer libro, cuando introduce uno de los "Cantos de Eurídice" con unas líneas en griego del Fedro que vendrían a decir: "los mayores bienes nos han llegado a través de la manía" (Fedro, 244, traducción propia). De este modo Luque reclama un lugar para el poeta iniciado, figura marginada por los poetas de la experiencia de los que, pese a haberse sentido próxima en un principio, poco a poco se distancia a la búsqueda de una voz propia y de su propia sentimentalidad ${ }^{3}$.

A esta misma concepción del poeta en relación directa con la del Fedro platónico se acerca María Sanz en Tu lumbre ajena con un poema que lleva por título una cita del filósofo latino Lucio Anneo Séneca: "Busca a esos amigos fieles que nunca te cerrarán las puertas de sus libros". Sin que en él encontremos la mención directa al filósofo ateniense, su presencia es más que 
clara. En el poemario en su conjunto la belleza se perfila como bálsamo para el espíritu y su contemplación desde la luz y el calor que desprenden las obras más excelsas del hombre, ajenas a la autoría de la voz poética pero suyas desde su contemplación, relativizan la amargura y el vacío existencial inherente en tantos momentos al ser humano. En el poema al que la cita de Séneca da título, los libros y en particular los de poesía, son ejemplo de dichas obras. La voz poética, a la par de manifestarse deudora de sus lecturas en la autoría de los poemas propios, admite que se acercó a los que llama "sus poetas" "sin los pies en el suelo" y afirma la "imposibilidad de ascender si no es por la palabra" (51). Una vez más encontramos la idea platónica de elevación, idea que se consolida al final del poema al calificar a los poetas como "arcángeles en verso" que "te ayudan a escapar sobre sus alas" (52).

En contrapartida, hay otra imagen del poeta, aquella que transmite el Platón de La República, que es sometida a crítica por varias voces del panorama poético actual, en la línea de la polémica que se encendió contra ella en el siglo XIX con la llamada ‘crisis de la razón', que obligaría hasta hoy a plantearse nuevamente las relaciones filosofía- poesía. Nietzsche, Heidegger, María Zambrano en nuestro país y, posteriormente, Deleuze han sido varios de los eslabones de una fase de la historia de la filosofía en la que esta se refunda a través del diálogo con las artes y, en particular, con la poesía ${ }^{4}$.

Pues bien, frente a la figura del poeta-iniciado Platón presenta en La República al poeta como ser que no hace sino imitar la realidad. El filósofo no encuentra lugar para este poeta en su ciudad ideal ya que será incapaz de alcanzar el mundo auténtico, el de las ideas, al limitarse únicamente a copiar con palabras el reflejo de aquellas en el mundo de los sentidos:

Y así fue justo no recibirle en una ciudad que debía ser regida por buenas leyes porque aviva y nutre ese elemento del alma (que no es el mejor) y, haciéndolo fuerte, acaba con la razón...De este modo, diremos, el poeta imitativo implanta privadamente un régimen perverso en el alma de cada uno condescendiendo con el elemento irracional que hay en ella. (605 b)

Observamos, pues, que lo que Platón censura en particular es la figura del poeta imitativo que corresponde, sobre todo, a la del poeta trágico. Recordemos la representación del lado irracional del individuo que ofrecen las piezas de Eurípides, a quien el filósofo pudo haber tenido en mente al escribir estos 
pasajes de su obra. Contrasta esta imagen con la que encontramos en el Fedro y a la que se siente afín Luque, pues en aquella la poesía está tan llena de pensamiento como la filosofía, separándose ambas, como bien anota Goyes, no por su grado de aproximación a la verdad sino por su modo de producirse: mediante la razón, en el caso de la filosofía, mediante la inspiración o manía en el caso de la poesía (4).

Es esa concepción del poeta de La República la que es sometida a revisión irónica en el poema de Alberto Tesán "Platón aconseja a un guardián de la República":

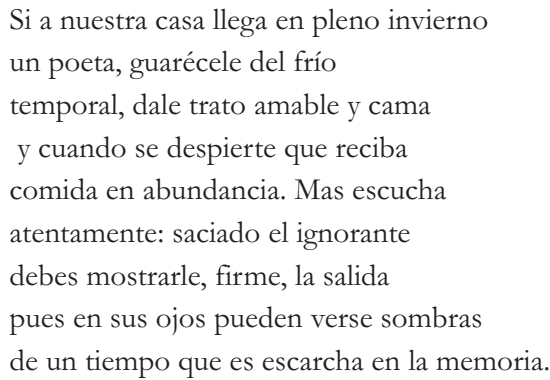

En él se presenta al poeta como un ser primario e ignorante del que deben ser saciadas las necesidades más básicas (hambre, sed, frío y sueño) por la hospitalidad de este guardián de la República y a petición de una voz poética que es la del propio filósofo. No obstante, tras ello, añade dicha voz, debe ser expulsado pues su mirada ha quedado penetrada por momentos de dolor o por pasiones de las que Platón recomienda mantenerse al margen. Al menos eso parece sugerir la alusión a la escarcha como metáfora que evoca el frío interior. Tesán lleva a cabo de este modo una reflexión metapoética sobre el papel del poeta y la función de la poesía. Y es que, a su modo de ver, "la poesía tiene que remover las entrañas del lector, hacer que sangre" (Poética, 2008), concepción que resulta obvio se sitúa en las antípodas del racionalismo platónico: el poeta nunca puede llegar al conocimiento real, aquel que radica en las ideas, pues sólo se limita a copiar la realidad exterior, reflejo de estas, o incluso a la copia deformada, lo que Platón llama simulacro. Ofrecer dichas copias y simulacros en sus obras no reporta al alma de quien las recibe beneficio alguno, ya que no conducen al conocimiento real. 
Al mundo de las ideas sólo accede el sabio y este, en su camino a la verdad, ha de alejarse de todo placer concupiscible. Esta concepción del platonismo la encontramos revertida en el poema de Josefa Parra "Xenócrates recuerda a una mujer". La voz poética, ficcionalizada en la de Xenócrates, filósofo sucesor de Espeusipo en la dirección de la Academia platónica, exclama al recordar el cuerpo desnudo de una mujer que sale del mar:

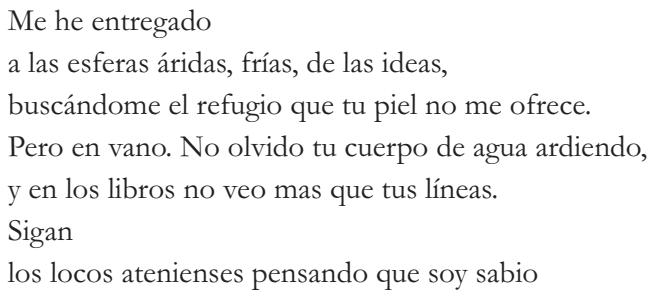

Parra recrea en el poema al prototipo de sabio platónico, entregado a la contemplación de las ideas, para revertirlo y hacer de él un individuo sensible a las pasiones. Para ello juega, dándole la vuelta, con la anécdota sobre el encuentro entre la hetera Friné, de belleza tan notoria que sirvió de modelo para la Venus de Milo de Praxíteles, transmitida en diferentes versiones por Diógenes Laercio y Valerio Máximo y recreada en la literatura por el poeta francés y estudioso de la antigüedad Pierre Loüys:

Era el día de las fiestas de Eleusis. Veinte mil personas llegadas de todas partes de Grecia se habían reunido en la playa cuando Friné avanzó hacia las olas y, apenas las tocaron sus pies, se despojó de su manto, desató su cinturón, se arrancó la túnica y "desanudando sus maravillosos cabellos, entró al mar. (Loüys 1963: 16)

Las fuentes griegas nos hablan de que ella trató de seducir sin éxito a Xenócrates, famoso por su continencia, quien fue caracterizado por la hetera de "estatua" al comprobar ella su imperturbabilidad (Diógenes Laercio IV, 1). Valerio Máximo califica su ejemplo de abstención como "propia de un alma llena de sabiduría" (Hechos y dichos memorables IV, 3, ext.3) pero Parra se empeña en sacar a la luz al hombre que esconde dicha estatua, el que vive obsesionado por la belleza del cuerpo de una mujer que nunca ha poseído. Para contrastar todavía más el hombre que es en realidad y el que se muestra a los demás, Parra utiliza la antítesis, enfrentando con ella "las frías ideas" a 
cuyo estudio se dedica el filósofo y el "cuerpo de agua ardiendo" de la mujer. Marca de este modo una notable oposición entre el frío raciocinio y el cálido ámbito de los sentimientos y emociones y establece con ella la poeta una crítica al racionalismo a ultranza.

No obstante, es Chantal Maillard en Matar a Platón quien de manera más elaborada articula dicha crítica en su calidad de poeta filósofa. Su poemario puede definirse, como Fernández Castillo acertadamente apunta, como "la transgresora respuesta de una poeta a la desautorización filosófica platónica de la palabra poética” (2), si bien va mucho más allá.

Maillard se propone, siguiendo las palabras de María Zambrano, cuya obra la poeta conoce a fondo y de la que sin duda se nutre, desarticular este idealismo radical en el que:

Había una formidable fuerza, la fuerza de estabilizar las perturbadoras apariencias, haciendo de ellas un mundo, un mundo por ser trasmundo. Y ese trasmundo ideal, arquitectura del ser que el pensamiento filosófico descubriera en Grecia con tan enérgica decisión, ha servido para que el hombre se sintiera habitante de un orbe estable, definido aunque ilimitado. (Zambrano, 2004, 97)

Y es desde aquí de donde parte una de las críticas de Maillard al platonismo. Ataca la autora su fuerza para crear este orden estable en medio de la multiplicidad de apariencias a las que el ser humano se enfrenta. Pero, por otra parte, no puede admitir que Platón descalifique sin más la palabra poética. Maillard, que ha dedicado parte de su actividad filosófica al estudio del concepto de 'razón poética' que introduce Zambrano en el panorama filosófico, comparte con esta la idea de que la más honda verdad se revela no por la pura razón sino a través de aquella (Zambrano, 2004, 154)5 y es que esa 'razón poética' la que rescata “las cosas y los acontecimientos no traducibles a razones” (Zambrano, 2001, 105). Únicamente gracias a ella se puede, no sólo reunificar 'yo' y 'vida' sino, en definitiva, rehumanizar al hombre "libre de la propia tiranía que le ha impuesto ... la supremacía de la razón” (Gallego, 3). La razón zambriana, en definitiva, su visión filosófica del mundo, encuentra un vehículo de transmisión en la palabra literaria, en particular, en el género de la confesión, y con ella, según Maillard "recupera la escucha en la escritura, para la escritura" y "aspira... a abrir un lugar que se ensanche como un claro en el medio del bosque" (Zambrano y la tradición, 3). 
Pero vayamos por partes y centrémonos en primer lugar en el tema de la multiplicidad de las apariencias que Platón se propuso encorsetar a través de su doctrina. Maillard precede su poemario de dos citas de Deleuze pertenecientes a su obra La lógica del sentido. La primera de ellas reza así: "El acontecimiento no es lo que ocurre (accidente), es en lo que ocurre lo expresado mismo que nos hace seña y nos espera (...) es lo que debe ser representado en lo que ocurre." (109). Y es a un acontecimiento y a la reflexión sobre este en torno a lo que se articula el poemario, dividido en dos partes en apariencia independientes, "Matar a Platón” y "Escribir". Y decimos en apariencia porque, pese a que el título de la segunda anticipe su carácter metapoético, este aspecto invade por doquier y da igualmente sentido a la primera parte. "Matar a Platón", la primera, consta de varios poemas, partiendo el inicial de un accidente vial. "Un hombre es aplastado", reza el primer verso, y a partir de ahí una voz poética en tercera persona describe la escena, abriendo camino a un juego de voces, la suya propia que a veces se transforma en un yo, y las de otros testigos del accidente que se van alternando en los diferentes poemas que la configuran. De este modo el acontecimiento inicial se va multiplicando bajo la mirada de diferentes ojos. Al mismo tiempo, el grupo de poemas se completa con una serie de subtítulos a pie de página cuya acción se desarrolla en los momentos previos al accidente, según deducimos al finalizar su lectura. Hemos de observar que Maillard añade como comentario al título del poemario "V.O. subtitulada", esto es, "versión original subtitulada", siguiendo una nomenclatura propia del cine. Pues bien, a través de ellos se incorpora una perspectiva más a lo acontecido y una nueva voz poética, el yo de una mujer, que complementa a las otras con su intervención. Los subtítulos contienen la esencia de la reflexión filosófica que plantea la totalidad del poemario, así como la razón básica de la elección del título. Lo que en el poemario ficticio del que hablan los subtítulos sucede, es lo que finalmente sucederá en los poemas que subtitula, si bien en ellos el muerto será un hombre y no una mujer como en aquel. La escritura, pues, se anticipa al acontecimiento y lo hace real.

Deleuze, cuyo pensamiento no debe perderse de vista a la hora de leer a Maillard, se apropia de la expresión de Nietzsche "invertir el platonismo" que no será para él sino dar validez a aquello a lo que Platón se la negó, esto es, al acontecimiento, a la copia desemejante a la idea, al denostado simulacro platónico. De ahí el “matar a Platón”, enfrentarse a ese empeño del griego de, 
en palabras de Martínez Mellado, "poner límites al devenir ilimitado, al devenir siempre otro, a lo que escapa a toda identidad y nos despoja de toda seguridad, exponiéndonos al caos y al azar" $(1987,12)$ o, como diría Zambrano al hablar de la crisis del pensamiento racional, de "humillar a la vida" (2001, 17-18). Y Maillard lo hace a través de la presentación de un acontecimiento que "acontece" de modo diferente ante los ojos de varios testigos que poco a poco se van multiplicando: la voz poética que aséptica, sin adorno, describe lo que sus ojos presencian, la niña que sujeta la mano del herido moribundo, un niño desnudo asomado a un balcón, su madre que, tapándole los ojos, lo aparta de allí, una mujer temblorosa y su acompañante que trata de tranquilizarla aportando estadísticas sobre muertes ocasionadas por ese tipo de accidentes y hasta el escritor austriaco Robert Musil que discute con el filósofo francés Michel Serres pues no considera admisible incluir dicha escena en un tratado filosófico. Así se justifica esta multiplicidad de puntos de vista en los subtítulos:

Un acontecimiento no es un hecho, sino algo muy sutil, simple y complejo al mismo tiempo. Por eso las variaciones. Por eso los poemas. Un poema puede sugerir el instante. $\mathrm{Y}$ en ese instante está el universo entero. (31-35)

De este modo logra Maillard dos propósitos. Por un lado reivindica el valor del poema como vehículo legítimo de pensamiento a través del que la realidad reticular se revela. Por otro, desmantela el fundamento del idealismo platónico y le resta el valor de verdad a la idea pues, como en sus versos nos dice, esta es sólo es una construcción de nuestro propio miedo a afrontar la vida:

Toda idea desmiente lo-que-ocurre.

Pero la construimos

por miedo a contemplar la enorme trama

de aquello que acontece en cada instante:

todo lo que acontece nos desborda

y no estamos seguros del refugio. (67) 
Llegados a este punto Maillard nos presenta una larga lista de razones para la escritura en esa segunda parte del poema titulada Escribir. Y volvemos al leerla a recordar una vez más al Platón de La República, a ese que nos dice en boca de Sócrates:

Y por lo que toca a los placeres amorosos y a la cólera y a todas las demás concupiscencias del alma, ya dolorosas, ya agradables, que decimos que siguen a cada una de nuestras acciones, ¿no produce la imitación poética esos mismos efectos en nosotros? Porque ella riega y nutre lo que había que dejar secar y erige como gobernante lo que debería ser gobernado a fin de que fuésemos mejores y más dichosos, no peores y más desdichados. (Rep. X, $606 \mathrm{~d}$ )

Una de las copias que hay que erradicar es la de aquello que hace sentir dolor. Pero para nuestra autora el dolor es previo incluso al acontecer. Deleuze afirma en su Lógica del sentido que los acontecimientos se efectúan en nosotros y "nos esperan y nos aspiran, nos hacen señas", lo que ve claramente representado en una cita de su admirado poeta francés Joe Bousquet, herido al final de la primera guerra mundial y recluido de por vida a causa de una parálisis: "Mi herida existía antes que yo. He nacido para reencarnarla." (Deleuze, 108). Maillard parece hacerse eco de ella en sus versos, pues considera necesario aprender a vivir con la herida y es, en última instancia, para curarla para lo que sirve la escritura:

\section{Escribir}

Para curar

En la carne abierta

En el dolor de todos

En esa muerte que mana

En mí y es la de todos

\section{(...)}

Escribir el dolor

Para proyectarlo

Para actuar sobre él con la palabra. (71-72)

La escritura para Maillard tiene, en definitiva, una función catártica, como la de aquella poesía imitativa censurada y vilipendiada por el Platón 
de La República por dar lugar en ella al acontecimiento, doloroso y trágico las más de las veces.

De lo dicho hasta aquí vemos que son varios los poetas que toman como punto de partida para su reflexión metapoética y existencial el acercamiento o apropiación de la figura del poeta ofrecida en el Fedro platónico, tal y como se aprecia en los casos de Luque y Sanz, o la crítica a la imagen del poeta que el filósofo presenta en La República. Se lleva a cabo esta última bien tomándola directamente como eje del poema, al estilo de Tesán y Parra, o bien desmantelándola a la par que la doctrina del filósofo mismo, como prefiere Maillard, con el objeto de llegar al reconocimiento de la verdad universal del dolor. Todos ellos son, no obstante, buen ejemplo de que todavía hoy la literatura y el pensamiento griego se mantienen vivos en los poetas de la España actual y de que estos enriquecen su obra a través de un diálogo que sigue y no dudamos seguirá siendo sumamente prolífico.

\section{NOTAS}

1 Recordemos su imprescindible Palimpsestos. En su primera versión comienza hablando de 'architextualidad' para evolucionar posteriormente al concepto de 'transtextualidad' que sería, cito la edición en inglés, "the textual trascendence of the text...all that sets the test in a relationship, whether obvious or concealed, with other texts" (1).

2 Véase, por ejemplo, el caso de Carlos Marzal y su particular interpretación del mito platónico en el poema "Caverna” perteneciente a su libro Metales pesados (2001).

3 Es interesante observar el hecho de que dichos poetas reclamaron la vuelta del concepto griego de poesía como mímesis, que es lo que caracteriza a la poesía trágica griega, y va a ser precisamente la figura de este poeta la que Platón censure, como veremos avanzado este trabajo, en su obra La República en oposición a la imagen del poeta que ofrece en El Fedro. Sobre la visión de la poesía en los poetas de la experiencia es de lectura necesaria el artículo de Luis García Montero "De la poesía como género de ficción". El poeta para ellos "no es un privilegiado intérprete de lo inefable, no hay misterio ontológico sino una identidad que se pronuncia con tono íntimo..." (Morante, 68).

4 Sobre este tema véase el artículo de María Antonia González Valerio (2003), "Filosofía y poesía en el pensamiento de María Zambrano”, en particular las páginas 17 y 18.

5 Hemos de aclarar que este concepto lo desarrolla Zambrano reflexionando en torno al caso español pues, al carecer nuestro país de pensamiento filosófico sistemático, según ella "el pensar español se ha vertido dispersamente, ametódicamente, en la novela, en la literatura, en la poesía" (154). 


\section{REFERENCIAS BIBLIOGRÁFICAS}

Bergua, J. B. (trad.) 1963. LouY̌s, P. Las canciones de Bilitis. La mujer y el pelele. Madrid: Ediciones Ibéricas.

Del Olmo, A., Díaz de Castro, F.J. (eds.) 2011. Versos robados. Tradición clásica en la lirica posmoderna peninsular. Sevilla: Renacimiento.

Deleuze, G. 1994. Lógica del sentido. Miguel Morey (Trad.) Barcelona: Planeta-De Agostini. Edición Electrónica de la Escuela de Filosofía Universidad ARCIS (mmm.philosophia.ch) [25 abril 2011]

Fernández Castillo, José L. 2009. "Poesía y filosofía en Matar a Platón de Chantal Maillard". Especulo, 42.

(http://www.ucm.es/info/especulo/numero42/maplaton.html) [5 mayo 2011]

Gallego, I. "Razón poética y confesión”. María Zambrano. Centro Virtual Cervantes. (http://cvc.cervantes.es/actcult/zambrano/acerca/gallego.htm\#nota9) [25 abril 2011]

García Montero, L. 1996. "De la poesía como género de ficción”, en Aguas territoriales. Valencia: Pre-textos.

Genette, G. 1977. Palimpsests: literature in the second degree. Newman, Ch. y Doubinsky, C. (trad.). Nebraska: University of Nebraska Press.

González Valerio, M. A. 2003. "Filosofía y poesía en el pensamiento de María Zambrano", Signos filosóficos 9: 17-24.

Goyes Narváez, J. C. 2002. "Poesía y filosofía: ¿Gradación de la verdad o del conocimiento?" Especulo 21. (http://www.ucm.es/info/especulo/numero21/poefilos.html) [25 abril 2011]

LuQue, A. 1982. Hiperiónida. Granada: Universidad de Granada.

- 1994. Carpe noctem. Madrid: Visor.

- 2003. Camaradas de Ícaro. Madrid: Visor.

LLEDÓ, E. (ed. y trad.) 1986. Platón. Diálogos. Vol. III: Fedón, Banquete, Fedro. Madrid: Gredos. Maillard, C. 2004. Matar a Platón. Barcelona: Tusquets.

— “Zambrano y la tradición” María Zambrano. Centro Virtual Cervantes. (http://cvc.cervantes.es/actcult/zambrano/acerca/maillard.htm\#nota) [25 abril 2011]

Martínez Mellado, A. 1987. G. Deleuze y la inversión del platonismo. Murcia: Universidad de Murcia. (http://www.tesisenred.net/handle/10803/10833) [29 mayo 2011]

MarZaL, C. 2001. Metales pesados. Barcelona: Tusquets.

Morante, J. L. (Ed.) 2011. Luis García Montero. Ropa de calle. Antología poética (19802008). Madrid: Cátedra.

PARRA, J. 1996. Elogio a la mala yerba. Madrid: Visor.

SANZ, M. 2001. Tu lumbre ajena. Madrid: Hiperión.

Tesán Argemí, A. 1996. El mismo hombre. Valencia: Pre-Textos.

- Poética. 2008. En Las afinidades electivas.

(http://lasafinidadeselectivas.blogspot.com/2008/03/alberto-tesn.html)

[15 mayo 2011] 
Zambrano, M. 2004. Pensamiento y poesía en la vida española. Gómez Blesa, M. (Ed.) Madrid: Biblioteca nueva.

- 2001. La confesión, género y método. Madrid: Siruela. 
